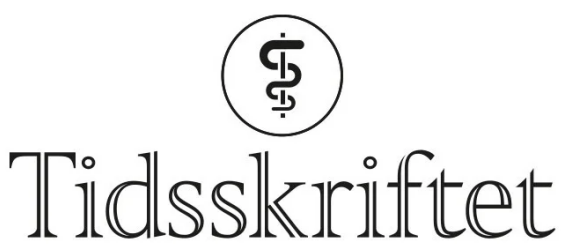

DEN NORSKE LEGEFORENING

\title{
Rehabilitering og sekundærforebygging etter hjerteinfarkt ved sykehus
}

\author{
KORT RAPPORT
}

\section{KARI PEERSEN}

kari.peersen@siv.no

Seksjon for hjertesykdommer

Medisinsk avdeling

Sykehuset i Vestfold

og

Avdeling for atferdsmedisin

Universitetet i Oslo

Hun har bidratt med idé, utforming, design, datainnsamling, dataanalyse, tolkning av data samt utarbeiding, revisjon og godkjenning av innsendte manus.

Kari Peersen er ph.d., fysioterapeut og postdoktor/forsker. Hun mottar interne forskningsmidler fra Sykehuset i Vestfold.

Forfatteren har fylt ut ICMJE-skjemaet og oppgir ingen interessekonflikter.

\section{JOHN MUNKHAUGEN}

Seksjon for hjertesykdommer

Medisinsk avdeling

Drammen sykehus

og

Avdeling for atferdsmedisin

Universitetet i Oslo

og

Oslo universitetssykehus, Ullevål

Han har bidratt med idé, utforming, design, datainnsamling, tolkning av data samt revisjon og godkjenning av innsendte manus.

John Munkhaugen er ph.d., utdanningskandidat i kardiologi og seniorforsker. Han er leder for forskningsgruppen NORCOR. Han mottar forskningsmidler fra Nasjonalforeningen for folkehelsen. Forfatteren har fylt ut ICMJE-skjemaet og oppgir følgende interessekonflikter: Han har mottatt foredragshonorar fra Sanofi, Amgen og Bayer.

\section{SIV JORUNN OLSEN}

Medisinsk avdeling

Universitetssykehuset Nord-Norge, Harstad

Hun har bidratt med tolkning av data samt revisjon og godkjenning av innsendte manus.

Siv Jorunn Olsen er ph.d., spesialsykepleier og postdoktor/forsker. Hun har mottatt forskningsmidler fra Helse Nord.

Forfatteren har fylt ut ICMJE-skjemaet og oppgir ingen interessekonflikter. 
Seksjon for hjertesykdommer

Medisinsk avdeling

Sykehuset i Vestfold

Han har bidratt med idé, utforming, design, datainnsamling, tolkning av data samt revisjon og godkjenning av innsendte manus.

Jan Erik Otterstad er ph.d., kardiolog og seniorforsker.

Forfatteren har fylt ut ICMJE-skjemaet og oppgir ingen interessekonflikter.

\section{ELISE SVERRE}

Seksjon for hjertesykdommer

Medisinsk avdeling

Drammen Sykehus

og

Avdeling for atferdsmedisin

Universitetet i Oslo

Hun har bidratt med idé, utforming, design, datainnsamling, dataanalyse, tolkning av data samt revisjon og godkjenning av innsendte manus.

Elise Sverre er ph.d., konstituert overlege i kardiologi og postdoktor/forsker. Hun mottar forskningsmidler fra stiftelsen Dam.

Forfatteren har fylt ut ICMJE-skjemaet og oppgir ingen interessekonflikter.

\section{BAKGRUNN}

I norske studier er det dokumentert dårlig kardiovaskulær risikofaktorkontroll og høy forekomst av nye hjerte- og karhendelser hos hjerteinfarktpasienter. Det foreligger lite kunnskap om omfang av sekundærforebyggende behandling og hjerterehabilitering ved norske sykehus. Vi ønsket derfor å gjennomføre en kartlegging av rutiner ved utskrivning og poliklinisk oppfølging etter hjerteinfarkt.

\section{MATERIALE OG METODE}

I oktober 2018 ble avdelingsoverleger på hjerteavdelinger og avdelingssykepleier/fysioterapeut på hjertepoliklinikker ved alle norske sykehus ( $\mathrm{N}=51)$ kontaktet med forespørsel om å delta i et telefonintervju.

\section{RESULTATER}

Til sammen 40 (78\%) leger og 51 (100\%) sykepleiere/fysioterapeuter gjennomførte telefonintervjuet. Elleve sykehus brukte standardiserte epikrisemaler med behandlingsmål og forventet oppfølging. Ti sykehus tilbød rutinemessig poliklinisk kontroll. 47 sykehus (92\%) tilbød tverrfaglig hjerterehabilitering, hjerteskole eller hjertetrening, og av disse tilbød ni (18\%) tverrfaglig, sammensatt hjerterehabilitering i henhold til internasjonale anbefalinger.

\section{FORTOLKNING}

Kartleggingen avdekket betydelige forskjeller i rapporterte rutiner ved utskrivning og tilbud om hjerterehabilitering og poliklinisk oppfølging ved norske sykehus.

\section{HOVEDFUNN}

Vi fant betydelig variasjon i rapporterte rutiner for utskrivning og omfang av hjerterehabilitering for pasienter etter akutt koronarsykdom.

Under $20 \%$ av norske sykehus tilbød tverrfaglig, sammensatt hjerterehabilitering. 
Hvert år rammes omtrent 12 ooo nordmenn av hjerteinfarkt (1), og av disse har en fjerdedel også tidligere hatt kransarteriesykdom (2) $)$. For å forebygge nye hendelser er det anbefalt at man overvåker og behandler de etablerte kardiovaskulære risikofaktorene (3). Norske data har vist at flertallet av pasienter etter hjerteinfarkt har dårlig risikofaktorkontroll (묘,4). Årsakene er sammensatte og kan være relatert til den enkelte pasient og oppfølgingen fra helsevesenet (3). Det foreligger et potensial for å optimalisere behandling av risikofaktorer og forbedre sykehusepikrisene med behandlingsmål og oppfølgingsplaner (4.).

Det er solid dokumentasjon for at deltakelse i tverrfaglig hjerterehabilitering er forbundet med forbedret livskvalitet og redusert sykelighet og dødelighet, også etter innføring av perkutan koronar intervensjon (PCI) og moderne medikamentell sekundærforebyggende behandling (3,.5). Europeiske retningslinjer anbefaler at hjerterehabiliteringen er tverrfaglig og omfatter trening, undervisning, oppfølging og håndtering av livsstil og risikofaktorer samt psykososial støtte (3). Tverrfaglig hjerterehabilitering etter hjerteinfarkt har høyeste anbefaling i retningslinjene (klasse $1 \mathrm{~A}$ ) (3). Til tross for dette er det få i Norge som tilbys eller deltar på ulike former for hjerterehabilitering (므), og det er betydelige forskjeller mellom sykehusene (7.).

Det foreligger lite kunnskap om rutiner ved utskrivning av hjerteinfarktpasienter og om sekundærforebyggende oppfølging og hjerterehabilitering i Norge. Formålet med studien var å skaffe en oversikt over eksisterende tilbud ved landets sykehus.

\section{Materiale og metode}

I tidsrommet 1.-14. oktober 2018 ble det tatt kontakt med avdelingsoverleger på hjerteavdelinger og avdelingssykepleier/fysioterapeut på hjertepoliklinikker ved alle landets 51 sykehus med forespørsel om å delta i et telefonintervju med en egenutviklet, detaljert intervjuguide (tabell 1). Rutiner ved utskrivning fra sykehus samt innhold og omfang av hjerterehabilitering og poliklinisk oppfølging ble kartlagt.

\section{Tabell 1}

Kartlegging av sekundærforebyggende behandling og oppfølging ved norske sykehus ( $\mathrm{N}=$ 51). Svarene angis i antall (\%)

\begin{tabular}{|c|c|c|}
\hline Spørsmål & Nei & $\mathrm{Ja}$ \\
\hline \multicolumn{3}{|l|}{ Spørsmål til avdelingsoverleger ( $n=40 / 51,78 \%)$} \\
\hline $\begin{array}{l}\text { Har avdelingen skriftlige prosedyrer for sekundærforebyggende } \\
\text { behandling og oppfølging? }\end{array}$ & $\begin{array}{c}16 \\
(40)\end{array}$ & $\begin{array}{c}24 \\
(60)\end{array}$ \\
\hline $\begin{array}{l}\text { Bruker legene standardisert epikrisemal med behandlingsmål for } \\
\text { risikofaktorer og forventet oppfølging etter utskrivning? }\end{array}$ & $\begin{array}{l}29 \\
(73)\end{array}$ & $11(28)$ \\
\hline $\begin{array}{l}\text { Henviser avdelingen systematisk hjerteinfarktpasienter til } \\
\text { hjerterehabilitering? }\end{array}$ & $7(18)$ & $\begin{array}{c}33 \\
(83)\end{array}$ \\
\hline $\begin{array}{l}\text { Settes infarktpasientene opp til rutinemessig kontroll etter } \\
\text { utskrivning? }^{1}\end{array}$ & $\begin{array}{l}30 \\
(75)\end{array}$ & $10(25)$ \\
\hline \multicolumn{3}{|l|}{ Spørsmål til avdelingssykepleier eller fysioterapeut ( $n=51 / 51,100 \%)$} \\
\hline $\begin{array}{l}\text { Har sykehuset hjerterehabilitering eller annen systematisk sykepleier- } \\
\text { eller fysioterapeutoppfølging av infarktpasienter etter utskrivning? } \\
\text { Hvis ja, beskriv innhold, varighet og hyppighet }{ }^{2}\end{array}$ & $4(8)$ & $\begin{array}{l}47 \\
(92)\end{array}$ \\
\hline Tverrfaglig, sammensatt hjerterehabilitering & $\begin{array}{l}42 \\
(82)\end{array}$ & $9(18)$ \\
\hline
\end{tabular}




\begin{tabular}{|ccc|}
\hline Spørsmål & Nei & Ja \\
\hline Hjerteskole og trening & 29 & 22 \\
& $(57)$ & $(43)$ \\
\hline Kun hjerteskole & $37(73)$ & $14(27)$ \\
\hline Kun trening & 49 & $2(4)$ \\
& $(96)$ & \\
\hline
\end{tabular}

${ }^{1}$ Oppfølgingsspørsmål: Hvis ja, hvor lenge etter utskrivning?

${ }^{2}$ Svarene ble kategorisert av forfatterne som vist under. Se metodedel for detaljer

De ulike hjerterehabiliteringstilbudene ble kategorisert med utgangspunkt i europeiske anbefalinger (3):

- Tverrfaglig, sammensatt hjerterehabilitering: tilbud der individuelle samtaler, trening og felles undervisning er integrert og tverrfaglig (lege, sykepleier, fysioterapeut og andre). Varighet 4-12 uker, ofte med tilbud om forlenget trening.

- Hjerteskole: tilbud om undervisning av ulike fagpersoner. Varighet 1-4 dager.

- Hjertetrening: tilbud om trening i regi av fysioterapeut. Varighet 6-12 uker.

\section{STATISTIKK OG ETIKK}

Materialet beskrives deskriptivt med antall og prosent, gjennomsnitt og spredning.

Kartleggingen inneholder ingen personopplysninger. Den omfatter helsetjenesteforskning og er således utenfor mandatet til Regional komité for medisinsk og helsefaglig forskningsetikk. Informantene ga muntlig samtykke til å delta i telefonintervjuet, og det ble understreket at data ikke ville bli presentert på sykehusnivå.

\section{Resultater}

Til sammen 40 av 51 (78\%) avdelingsoverleger på hjerteavdelingene og 51 (100\%) sykepleiere/fysioterapeuter på hjertepoliklinikkene besvarte telefonintervjuet (tabell 1). I noen tilfeller snakket vi med både sykepleier og fysioterapeut. Det var ingen diskrepans i svarene fra de ulike yrkesgruppene. 24 (6o \%) av 40 sykehus som svarte, hadde skriftlige prosedyrer for sekundærforebyggende behandling og oppfølging (tabell 1). Standardisert epikrisemal med behandlingsmål og forventet oppfølging var tilgjengelig ved 11 ( $28 \%$ ) sykehus. De fleste oppga at hjerteinfarktpasienter ble henvist til hjerterehabilitering, mens $10(25 \%)$ sykehus satte opp hjerteinfarktpasienter til rutinemessig kontroll på poliklinikken hos lege eller sykepleier, etter gjennomsnittlig 15 (spredning 2-52) uker.

47 (92\%) sykehus hadde poliklinisk tilbud om tverrfaglig hjerterehabilitering, hjerteskole eller hjertetrening (tabell 1). 36 ( $71 \%$ ) sykehus tilbød hjerteskole, med gjennomsnittlig 2 (spredning 1-4) dagers varighet, 33 (65\%) sykehus tilbød trening i regi av fysioterapeut gjennomsnittlig 19 (spredning 2-48) ganger. Tverrfaglig hjerterehabilitering ble tilbudt ved $9(18 \%)$ sykehus med varighet i gjennomsnitt 11 (spredning 5-18) ganger, 1-3 ganger i uken.

\section{Diskusjon}

Vi fant betydelig variasjon mellom sykehus i rutiner for utskrivning og omfang av hjerterehabilitering for pasienter etter hjerteinfarkt. Et mindretall av sykehusene benyttet standardisert epikrisemal eller satte opp pasientene til rutinemessig poliklinisk kontroll. 
De fleste sykehusene tilbød en eller annen form for systematisk oppfølging, mens kun ni av 51 sykehus hadde tilbud om tverrfaglig, sammensatt hjerterehabilitering som anbefalt i europeiske retningslinjer (3).

Manglende riskofaktorkontroll og høy forekomst av nye hjerte- og karhendelser hos hjerteinfarktpasienter understreker behovet for tettere sekundærforebyggende oppfølging $(\underline{2}, 4$.). I tillegg til endringer i flere anbefalte behandlingsmål og utvikling av nye sekundærforebyggende medikamenter er det i større grad enn tidligere anbefalt skreddersydd behandling basert på pasientens egne ønsker, alder, tilleggssykdommer og risikoprofil (3). Dette er argumenter for at sykehusene bør ta et større ansvar også for oppfølgingen av sekundærprofylakse etter utskrivning. Imidlertid så vi i undersøkelsen, til tross for dokumentert god effekt på medikamentetterlevelse og livsstilsendringer (므), at kun et fåtall av sykehusene tilbød rutinemessig poliklinisk oppfølging etter hjerteinfarkt. Videre etterspør fastlegene, som er hovedansvarlige for oppfølgingen, mer detaljert informasjon om behandling og forventet oppfølging (4). Bruk av standardiserte epikrisemaler kan være et viktig verktøy for å sikre god informasjonsoverføring mellom behandlingsnivåene.

Hjerterehabilitering er forbundet med svært gunstige kliniske og helseøkonomiske effekter og reduserer total død med 20-6o \% etter median 24 måneders oppfølging (5). Til tross for at de fleste sykehus i vår studie oppga at pasienter ble henvist til hjerterehabilitering, var deltakerandelen blant PCI-behandlede pasienter i NORSTENTstudien kun 28 \% (ㅁ) . Mulige forklaringer på denne betydelige divergensen kan skyldes lang reiseavstand, manglende tilbud eller kapasitet, mangelfulle henvisningsrutiner eller lav motivasjon hos pasienten. Sykehuset i Vestfold har praktisert systematisk henvisning, med $75 \%$ deltakelse på hjerterehabilitering som resultat (7.).

Systembarrierer som manglende rutiner for henvisning og lav tilgjengelighet av tilbud er sannsynligvis de viktigste årsakene til den lave deltakerandelen i Norge. Kun $18 \%$ av sykehusene tilbød tverrfaglig hjerterehabilitering i tråd med europeiske anbefalinger (3), mens $27 \%$ hadde hjerteskole uten trening og $8 \%$ ikke hadde noe tilbud om oppfølging. Det foreligger således et klart behov for å bygge ut hjerterehabiliteringstilbudene ved norske sykehus. Det er behov for videre forskning på henvisningsrutiner, barrierer for deltakelse, innhold og kvalitet på de ulike hjerterehabiliteringstilbudene samt evaluering av digitale rehabiliteringsprogram. Et register for å evaluere og forbedre hjerterehabilitering er anbefalt (3), men foreløpig ikke etablert i Norge. Sverige har et slikt register med mulighet til å evaluere effekten av hjerterehabiliteringens kvalitet og tilgjengelighet på nye hjertehendelser, livskvalitet og overlevelse (9.).

Denne unders $ø$ kelsen benyttet en egenutviklet intervjuguide med mange lukkede spørsmål og lite rom for utdyping av svarene. Det er derfor mulig at viktig informasjon om sekundærforebyggende oppfølging ikke ble avdekket. Spørsmålene var ikke validerte eller benyttet i tidligere studier. Elleve av avdelingsoverlegene lyktes vi ikke å få kontakt med. Undersøkelsen ble gjennomført høsten 2018, og det kan ha skjedd endringer i rutinene etter det, men det er liten grunn til å tro at det har vært store endringer ut over koronaepidemitiltak.

KONKLUSJON

Vår kartlegging avdekket store variasjoner i rapporterte rutiner ved utskrivning og i innhold og omfang av hjerterehabilitering og poliklinisk oppfølging ved norske sykehus. Studien kan bidra til å sette fokus på sekundærprofylakse og hjerterehabilitering og medvirke til at tilbudene bygges ut og forbedres kvalitetsmessig. 


\section{LITTERATUR}

1. Norsk hjerteinfarktregister. Trondheim: St. Olavs hospital, 2019.

https://www.kvalitetsregistre.no/sites/default/files/2_arsrapport_2019_norsk_hjerteinfarktregister.p df Lest 30.8.2021.

2. Jortveit J, Halvorsen S, Kaldal A et al. Unsatisfactory risk factor control and high rate of new cardiovascular events in patients with myocardial infarction and prior coronary artery disease. BMC Cardiovasc Disord 2019; 19: 71. [PubMed][CrossRef]

3. Ambrosetti M, Abreu A, Corrà U et al. Secondary prevention through comprehensive cardiovascular rehabilitation: 2020 update. A position paper from the Secondary Prevention and Rehabilitation Section of the EAPC. Eur J Prev Cardiol 2020; 27: 2047487320913379. [CrossRef]

4. Munkhaugen J, Peersen K, Sverre E et al. Oppfølging etter hjerteinfarkt - er den god nok? Tidsskr Nor Legeforen 2018; 138. doi:10.4045/tidsskr.17.1050. [PubMed][CrossRef]

5. van Halewijn G, Deckers J, Tay HY et al. Lessons from contemporary trials of cardiovascular prevention and rehabilitation: A systematic review and meta-analysis. Int J Cardiol 2017; 232: 294-303. [PubMed][CrossRef]

6. Olsen SJ, Schirmer H, Bønaa KH et al. Cardiac rehabilitation after percutaneous coronary intervention: Results from a nationwide survey. Eur J Cardiovasc Nurs 2018; 17: 273-9. [PubMed] [CrossRef]

7. Peersen K, Munkhaugen J, Gullestad L et al. The role of cardiac rehabilitation in secondary prevention after coronary events. Eur J Prev Cardiol 2017; 24: 136o-8. [PubMed][CrossRef]

8. Jørstad HT, Snaterse M, Ter Hoeve N et al. The scientific basis for secondary prevention of coronary artery disease: recent contributions from the Netherlands. Neth Heart J 2020; 28 (suppl 1): 136-40. [PubMed][CrossRef]

9. Bäck M, Leosdottir M, Hagström E et al. The SWEDEHEART secondary prevention and cardiac rehabilitation registry (SWEDEHEART CR registry). Eur Heart J Qual Care Clin Outcomes 2021; 7: 431-7. [PubMed][CrossRef]

Publisert: 25. oktober 2021. Tidsskr Nor Legeforen. DOI: 10.4045/tidsskr.21.0349

Mottatt 28.4.2021, første revisjon innsendt 28.6.2021, godkjent 3.9.2021.

Publisert under åpen tilgang CC BY-ND. Lastet ned fra tidsskriftet.no 26. april 2023. 